\title{
Title: Pancreatic adenocarcinoma presenting as subacute cutaneous lupus, tripe palms and acanthosis nigricans maligna
}

Short running title: Paraneoplastic subacute cutaneous lupus

Authors: Tom Kovitwanichkanont ${ }^{1,2}$; Saurabh Prakash ${ }^{3}$; Alvin H. Chong ${ }^{1,4}$

${ }^{1}$ Skin Health Institute, Melbourne, Australia

2Department of Dermatology, Peter MacCallum Cancer Centre, Melbourne, Australia ${ }^{3}$ Department of Anatomical Pathology, Melbourne Pathology, Melbourne, Australia ${ }^{4}$ Department of Dermatology, St Vincent's Hospital, Melbourne, Australia

Word count: 406

Corresponding author's details:

Name: Dr Tom Kovitwanichkanont

Contact email: tom.kovitwanichkanont@gmail.com

Full postal address: 1/80 Drummond St, Carlton, VIC 3053 Australia

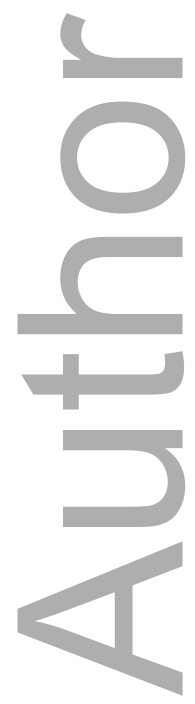

This is the author manuscript accepted for publication and has undergone full peer review but has not been through the copyediting, typesetting, pagination and proofreading process, which may lead to differences between this version and the Version of Record. Please cite this article as doi: $10.1111 /$ AJD.13409

This article is protected by copyright. All rights reserved 
Article type : Case Letter

A 66-year-old female presented with a three-month history of widespread polycyclic rash in a photosensitive distribution (Figure 1). She reported no arthralgia or muscle weakness and had no metabolic, oncological, autoimmune or medication history. Serology revealed positive antinuclear antibody (ANA) 1:160 speckled pattern and positive extractable nuclear antigen Ro autoantibodies. Creatinine kinase was within normal limits.

Histopathology of the annular plaques revealed mild acanthosis and vacuolar alteration of the basal layer with apoptotic keratinocytes. The dermis shows perivascular lymphocytic infiltrate, sparse interstitial eosinophils and scant dermal mucin. In this biopsy, the presence of mild acanthosis and density of inflammation slightly favoured subacute cutaneous lupus erythematosus (SCLE) rather than dermatomyositis. Eosinophils can be seen in both conditions, particularly drug induced forms. Given the clinical presentation of polycyclic plaques, absence of myositis, positive serologic markers, a clinicopathological diagnosis of SCLE-like eruption was made. Her rash was recalcitrant to high-dose oral and topical corticosteroid, hydroxychloroquine and methotrexate.

On review ten weeks later, she was noted to have papillomatous excrescences of the oral commissures (Figure 2A) and velvety hyperpigmentation involving the flexural regions consistent with acanthosis nigricans. On her palms and soles, she also had accentuation of the dermatoglyphic ridges and sulci, resembling "tripe palms" (Figure 2B). She had no constitutional symptoms to suggest an underlying oncological problem. 
Paraneoplasia was suspected. Total-body positron emission tomography/computed tomography (PET/CT) and a subsequent lymph node biopsy revealed a diagnosis of metastatic pancreatic ductal adenocarcinoma. She underwent palliative chemotherapy, including gemcitabine, oxaliplatin and a combination regimen consisting of folinic acid, fluorouracil and irinotecan (FOLFIRI). Both her oncological disease and skin manifestation did not significantly respond to the therapy. She ultimately succumbed to metastatic disease.

While SCLE is traditionally classified as idiopathic or drug-induced, there are case reports associating it with various malignancies, most commonly lung, breast and gastrointestinal tract. ${ }^{1,2}$ There are also cases of SCLE that were presumed to be induced by gemcitabine in patients with pancreatic cancer and breast cancer. ${ }^{3,4} \mathrm{It}$ is possible that SCLE-like rash in these cases may have represented a paraneoplastic phenomenon. Given the rarity of paraneoplastic correlation, a classic appearance of SCLE in a healthy patient may not warrant a search for an occult malignancy. However, this report highlights the importance of considering paraneoplastic syndrome, especially if it occurs abruptly in older patients, demonstrates refractory response to conventional therapy and when associated with other well-recognized paraneoplastic dermatoses, such as tripe palms (acanthosis palmaris) or acanthosis nigricans maligna.

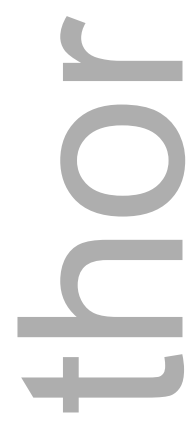

\section{References}

1. Shaheen B, Milne G, Shaffrali F. Subacute cutaneous lupus erythematosus associated with breast carcinoma. Clin Exp Dermatol. 2009;34(7):e480-1.

2. Koritala T, Tworek J, Schapiro B, Zolotarevsky E. Paraneoplastic cutaneous lupus secondary to esophageal squamous cell carcinoma. J Gastrointest Oncol. 2015;6(3):E61-E5. 
3. Cornacchia MA, Coromilas AJ, Gallitano SM, Frank RC, Halasz CL. Subacute cutaneous lupus erythematosus induced by gemcitabine in 2 patients with pancreatic cancer. JAAD Case Rep. 2019;5(7):596-601.

4. Wiznia LE, Subtil A, Choi JN. Subacute cutaneous lupus erythematosus induced by chemotherapy: gemcitabine as a causative agent. JAMA Dermatol. 2013;149(9):1071-5.

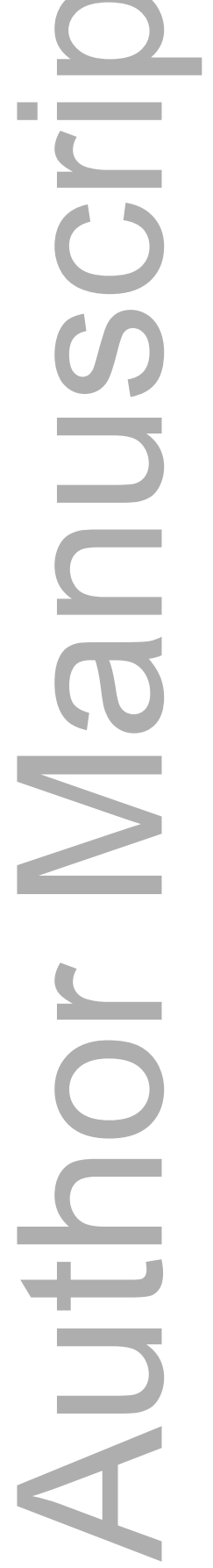



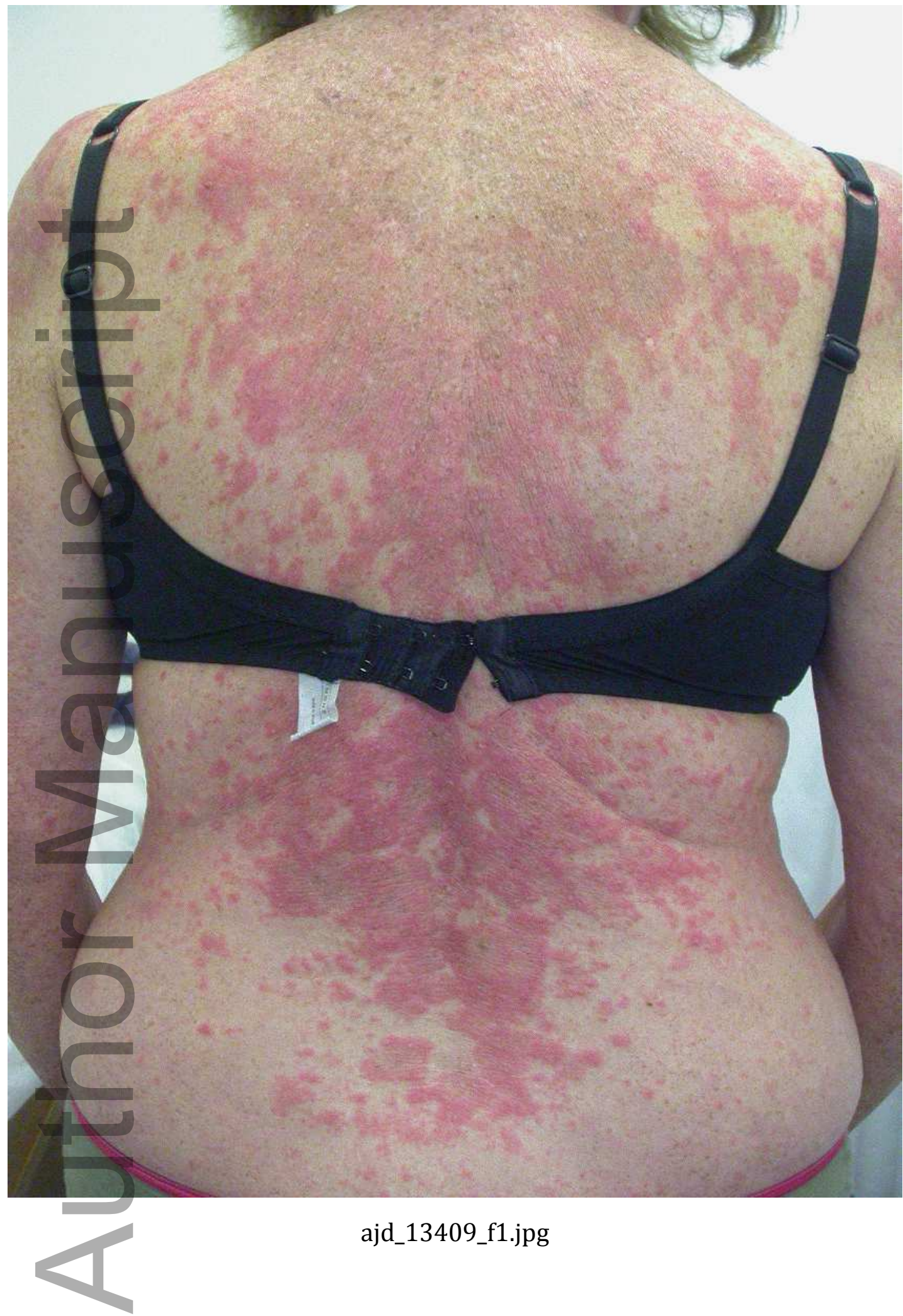

ajd_13409_f1.jpg 


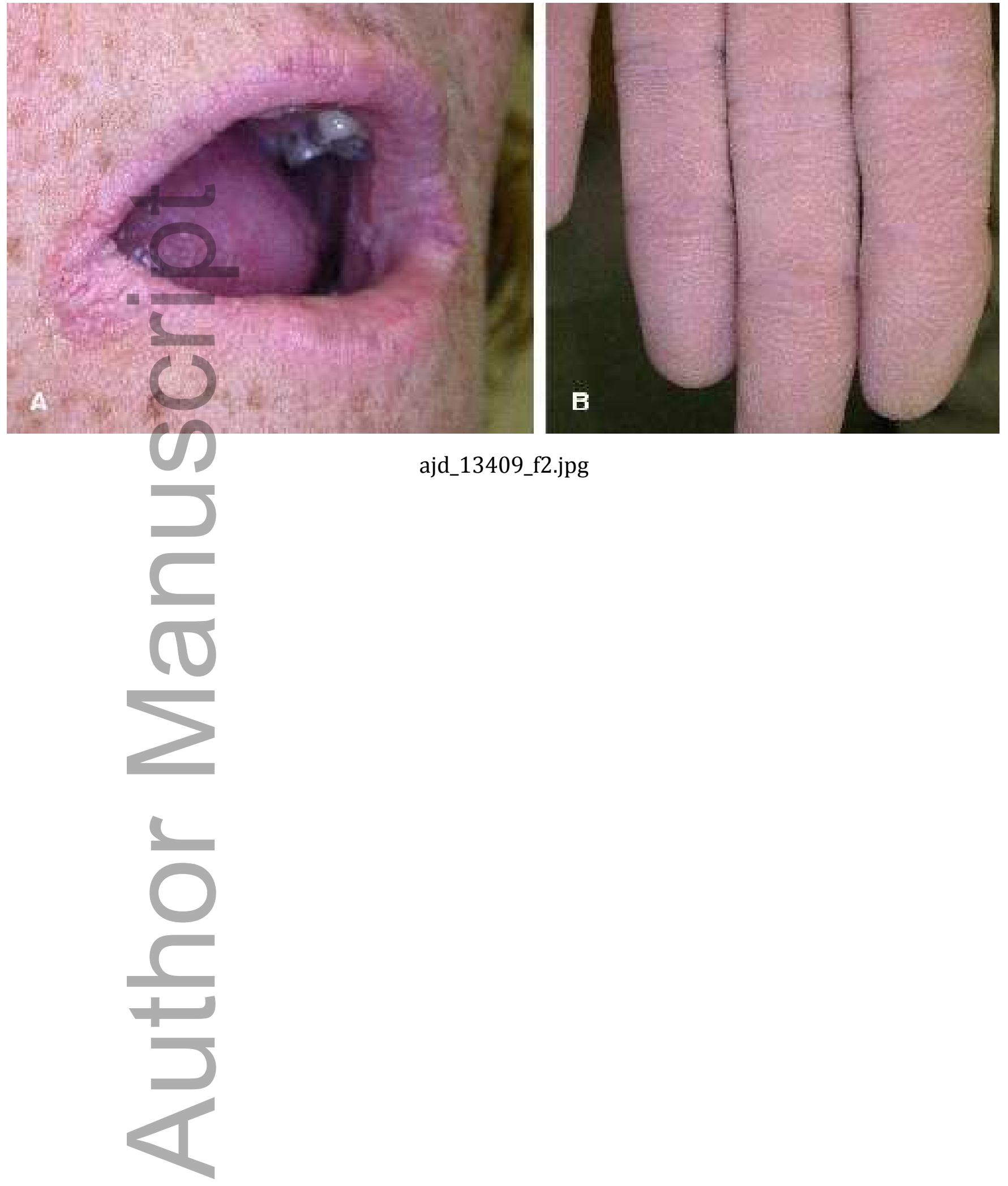

This article is protected by copyright. All rights reserved 

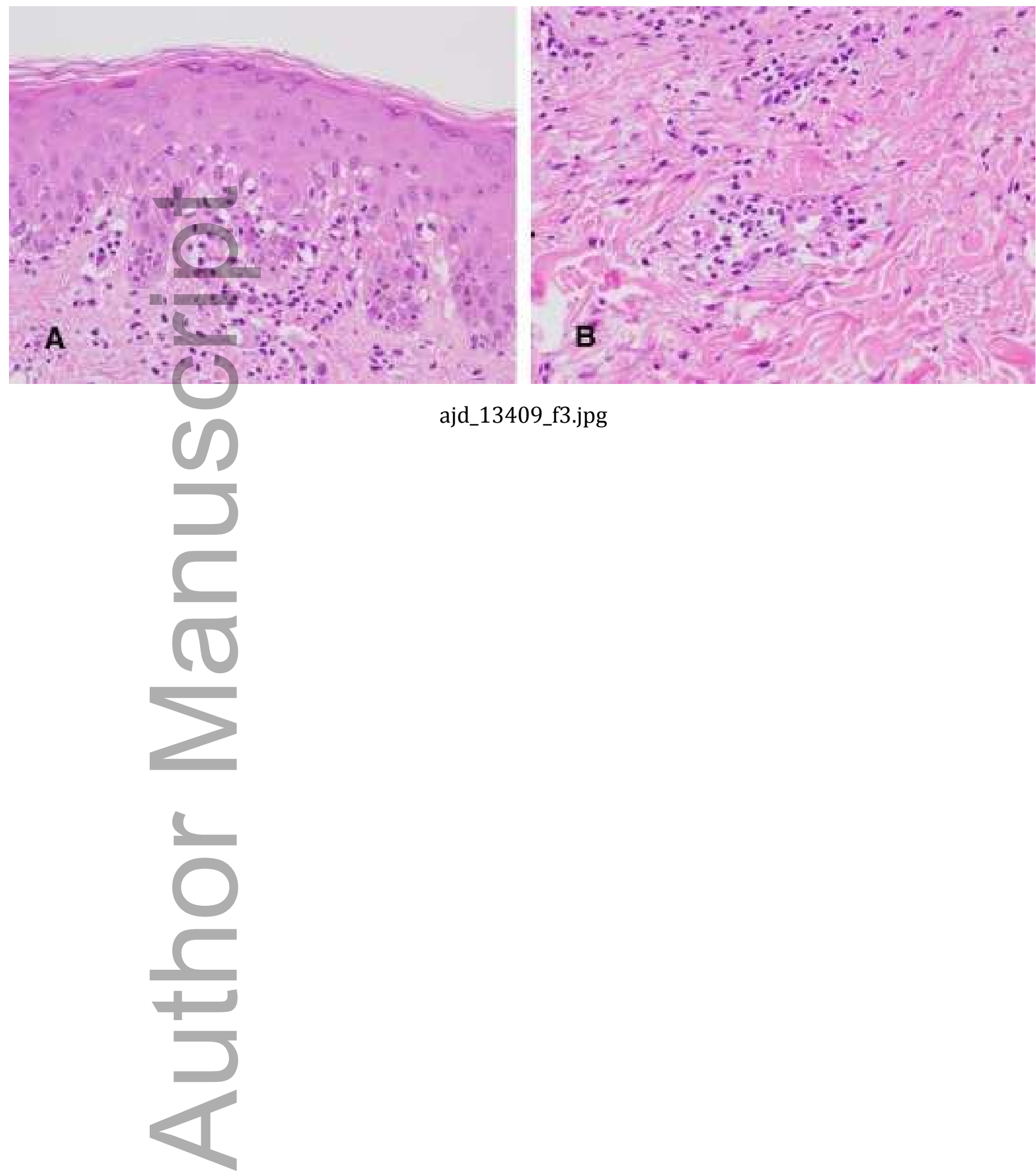

ajd_13409_f3.jpg

This article is protected by copyright. All rights reserved 


\section{University Library}

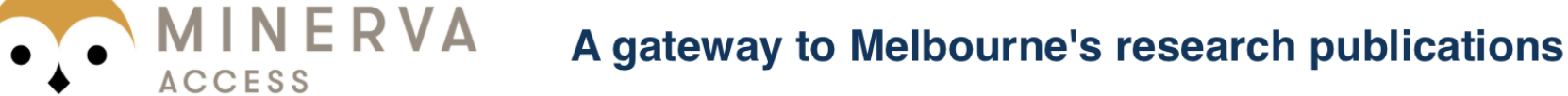

Minerva Access is the Institutional Repository of The University of Melbourne

Author/s:

Kovitwanichkanont, T;Prakash, S;Chong, AH

Title:

Pancreatic adenocarcinoma presenting as subacute cutaneous lupus, tripe palms and acanthosis nigricans maligna.

Date:

2021-02

Citation:

Kovitwanichkanont, T., Prakash, S. \& Chong, A. H. (2021). Pancreatic adenocarcinoma presenting as subacute cutaneous lupus, tripe palms and acanthosis nigricans maligna. Australas J Dermatol, 62 (1), pp.e132-e133. https://doi.org/10.1111/ajd.13409.

Persistent Link:

http://hdl.handle.net/11343/276038 